\author{
David Adler · Nimira Kanji · Kiril Trpkov \\ Gordon Fick · Rhiannon M. Hughes
}

\title{
HPC2/ELAC2 gene variants associated with incident prostate cancer
}

Received: 26 June 2003/ Accepted: 25 September 2003/Published online: 19 November 2003

(C) The Japan Society of Human Genetics and Springer-Verlag 2003

\begin{abstract}
The HPC2/ELAC2 gene on chromosome $17 \mathrm{p} 11$ was identified as a candidate gene for hereditary prostate cancer (HPC) susceptibility. Two HPC2 gene missense variants, Ser217Leu (Leu217) and Ala541Thr (Thr541) have been associated with incident prostate cancer cases in some studies, but not in others. We tested for possible associations between the two HPC2 gene variants and prostate cancer risk in incident prostate cancer cases (199) and healthy male controls (525) from the Calgary region. The Thr541 variant showed linkage disequilibrium with the Leu217 variant. The number of Leu217 homozygotes in the case and control groups (8.6versus $8.5 \%$ ) was not statistically different. Leu217 carrier status was associated with prostate cancer risk (cases 61.8\% versus controls 50.3\%) (OR 1.6, 95\% CI 1.15-2.23). Additional analysis found that this association was not due to the co-existence of Thr541 variant (OR1.59, $\mathrm{P}=0.009)$. Logistic regression found that the relationship between the log odds of being a Thr541carrier and age depends on case/control status. Thr541 carriers had an increased risk for late-onset prostate cancer $(P=0.028)$. Prostate intraepithelial neoplasia (PIN) was more common in the Leu217 allele carriers compared to non-carriers (42.3 versus $26.7 \%$ ) (OR 2.05, 95\% CI 1.10-3.83), and in the Thr541 carriers compared to non-carriers (50.0 versus $34.6 \%$ ) (OR 1.89,
\end{abstract}

D. Adler $\cdot$ N. Kanji $\cdot$ R. M. Hughes $(\bowtie)$

Southern Alberta Cancer Research Centre,

Department of Oncology, University of Calgary,

Room 300 Heritage Medical Research Building,

3330 Hospital Dr. NW, Calgary, Alberta,

T2 N 4N1, Canada

e-mail: rhughesb@ucalgary.ca

Tel.: + 1-403-2207664

Fax: + 1-403-2838727

K. Trpkov

Departments of Pathology and Laboratory Medicine,

University of Calgary, Calgary, Alberta, Canada

G. Fick

Department of Community Health Sciences,

University of Calgary, Calgary, Alberta, Canada
95\% CI 0.75-4.78). In summary, the HPC 2 gene variants Leu217 and Thr541 were associated with an increased risk for prostate cancer and for PIN in males undergoing radical prostatectomies in the Calgary region.

Key words HPC2/ELAC2 - Genotype · Leu217 · Ser541 - Prostate cancer $\cdot$ Prostate intraepithelial neoplasia

\section{Introduction}

The HPC2/ELAC2 gene on chromosome $17 \mathrm{p} 11$ was identified as the first candidate gene for hereditary prostate cancer susceptibility (Tavtigian et al.2000; Rebbeck et al. 2000). Positional cloning and mutation screening identified two mutations that segregated with prostate cancer in two high-risk pedigrees (Tavtigian et al. 2000). In addition, two missense variants (Ser217Leu and Ala541Thr) were associated with incident prostate cancer cases. Leu217 homozygotes were more frequent in the case group $(13.3 \%)$ than the controls $(6.1 \%)$ ) (OR 2.4, $P=0.0261)$. Thr541 carriers were more frequent in the case group $(9.8 \%)$ than the controls $(3.4 \%)$ (OR 3.1, $P=0.02)$. The Thr541 variant showed linkage disequilibrium, as it was only observed in the presence of the Leu217 variant (Tavtigian et al. 2000; Rebbeck et al. 2000). No significant differences were observed in the frequencies of the Leu217 and Thr541 variants between whites and blacks (Rebbeck et al. 2000). In a study of 359 incident prostate cancer cases and 266 male controls matched for age and race, $7.5 \%$ of cases and $3.5 \%$ of controls carried both variants (OR 2.37; 95\% CI 1.065.29). Survival analysis of cases carrying both variants showed a significant decrease in length of survival compared to non-carriers (Tavtigian et al. 2000).

Suarez et al. (2001) found a significantly greater carrier frequency of the Thr541 variant in incident prostate cancer cases $(9.7 \%)$ compared to controls $(3.7 \%)(P=0.008)$. Wang et al. (2001) reported no 
statistically significant difference in the frequency of the Leu217 allele $(32.3 \%$ cases versus $31.8 \%$ controls) or Thr541 allele (5.4\% cases versus $5.2 \%$ controls). However, they identified a novel Glu216Stop non-sense mutation in two out of three affected male relatives. Xu et al. (2001) found no statistical difference between the number of Thr541 carriers with hereditary prostate cancer $(10.5 \%)$, sporadic prostate cancer $(9.0 \%)$ or unaffected controls $(9.0 \%)$. Vesprini et al. (2001) found the prevalence of the Thr541 allele to be similar in men with prostate cancer $(6.8 \%)$, other prostate conditions $(6.8 \%)$ and healthy women $(6.3 \%)$. Rökman et al. (2001) reported no significant difference between the Thr541 allele frequency in hereditary prostate cancer patients $(7.5 \%)$, unselected prostate cancer patients $(7.5 \%)$ and controls $(7.4 \%)$ from Finland. However, they identified a novel HPC2 Glu622Val missense variant in exon 20 that was detected in $1.0 \%$ of control blood samples and $3.0 \%$ of unselected prostate cancer patients (OR 2.94; 95\% CI 1.05-8.23). A study of Afro-Caribbean males from Tobago found no significant difference in HPC2 allele frequencies between cases and controls (Shea et al. 2002). A case-control study from Japan determined that both HPC2 alleles were associated with significantly increased risk for prostate cancer (Leu217, $P=0.0012$; Thr541, $P=0.0145$ ) (Fujiwara et al. 2002). A recent study from the United Kingdom found no significant difference in the Thr541 variant and incident prostate cancer cases (Meitz et al. 2002). The objective of this study was to determine if there was an association between HPC2 Leu217 and Thr541 alleles with incident prostate cancer cases (radical prostatectomy specimens) from the Calgary region.

\section{Materials and methods}

\section{Study subjects}

Anonymous control blood samples were obtained from 525 randomly chosen healthy males undergoing routine haematology (complete blood count) investigations at the Calgary Laboratory Services (CLS) facility from 2001 to 2002. Samples collected for testing related to cancer diagnosis or detection were excluded. The average age of the control males was $61.5 \pm 11.2$ SD (range 41-92 years). DNA was prepared from 199 incident prostate cancer cases using paraffin-embedded tissue removed by radical prostatectomy during the year 2000 (KT, Prostate Cancer Tissue Bank, Rockview General Hospital, Calgary). The total number of radical prostatectomies performed that year at the hospital was 202 . The average age of the cases was 60.7 years \pm 6.3 SD (range 43-75 years). Pathological staging was T2a (19.1\%), T2b (78.9\%), and unknown $(2.0 \%)$. The average Gleason scores were 3.3 major $( \pm 0.5 \mathrm{SD})$ and 3.5 minor $( \pm 0.6 \mathrm{SD})$. Analysis was performed after patient names and personal identifiers were removed and replaced with coded numbers. The ethnic background of the cases was $95 \%$ white, $3.5 \%$ Asian and 1\% black. This approximates the ethnic distribution in the Calgary region (Statistics Canada, 1996).

\section{DNA isolation}

Genomic DNA was isolated from whole-blood samples (collected in EDTA) using the QIAamp DNA Mini kit (No. 51340, Qiagen
Inc. Mississauga, ON, Canada) or a salting out procedure (Helms 1990). The DNA was resuspended in $200 \mu$ of TE buffer $(10 \mathrm{mM}$ Tris, $1 \mathrm{mM}$ EDTA, pH 7.5) and stored at $4^{\circ} \mathrm{C}$. DNA was isolated from paraffin-embedded prostate tissue sections using the QIAamp kit described above. Prior to DNA isolation, three $25 \mu \mathrm{m}$ sections were placed in $2 \mathrm{ml}$ microfuge tubes, and the paraffin was dissolved in $1.2 \mathrm{ml}$ of xylene at $20^{\circ} \mathrm{C}$. Samples were centrifuged at $14,000 \mathrm{rpm}$ for $5 \mathrm{~min}$ at $20^{\circ} \mathrm{C}$. The tissue pellet washed twice using $1.2 \mathrm{ml}$ of $99 \% \mathrm{ETOH}$ at $20^{\circ} \mathrm{C}\left(14,000 \mathrm{rpm} \times 5 \mathrm{~min}\right.$ at $\left.20^{\circ} \mathrm{C}\right)$, and DNA was then isolated using the kit procedure.

\section{Genotyping}

Primer sequences for amplifying the coding regions and intronexon boundaries of HPC2 were derived from the genomic sequence (Tavtigian et al. 2000). All PCR reactions were carried out in $25 \mu \mathrm{l}$ volumes using a master mix of $2.5 \mu \mathrm{l}$ of $10 \times \mathrm{PCR}$ buffer minus $\mathrm{MgSO}_{4}, 1 \mu \mathrm{l}$ of $50 \mathrm{mM} \mathrm{MgSO} 0_{4}, 4 \mu \mathrm{l}$ of $10 \mathrm{mM}$ dNTPs, $2 \mu \mathrm{l}$ of each PCR primer $(10 \mathrm{pmol} / \mu \mathrm{l}), 0.5 \mu \mathrm{l}$ of recombinant Taq DNA Polymerase (GibcoBRL) and $11 \mu \mathrm{l}$ of distilled water. PCR amplifications of the DNA regions containing the polymorphisms of interest were performed using a method modified from Tavtigian et al. (2000): $95^{\circ} \mathrm{C}$ for $3 \mathrm{~min} ;\left(96^{\circ} \mathrm{C}\right.$ for $30 \mathrm{~s}, 55^{\circ} \mathrm{C}$ for $35 \mathrm{~s}, 72^{\circ} \mathrm{C}$ for $\left.45 \mathrm{~s}\right)$ for 35 cycles; $72^{\circ} \mathrm{C}$ for $10 \mathrm{~min}$. PCR amplification of the fragment containing the Ser217Thr variant was carried out using two different combinations of primers: blood $-\mathrm{m} 5 \mathrm{~B}$ (5'-GTTTTCCC AGTCACGACGCATTC CCATGTATGAACGTCT) and m5Q (5'- AGGAAACAGCTATGACCATCTACAAGCATTA CAAG GCAGAG); tissue - m5C (5'-AACAGAGGAGGGGAAAGCAC) and $\mathrm{m} 5 \mathrm{Q}$ (as above).

PCR amplification produced a 276-bp fragment for the blood DNA and a $209 \mathrm{bp}$ fragment for the tissue DNA. The PCR product $(15-20 \mu \mathrm{l})$ was digested overnight with $\operatorname{Taq} \mathrm{I} \alpha$ (New England Biolabs, Mississauga, ON, Canada) at $65^{\circ} \mathrm{C}$. PCR amplification of the fragment containing the Ala541Thr variant was performed using two different combinations of primers: bloodm15A (5'- CCAGC CTTTGTGTAAGTCTAC) and m15RFLP (5'- AATTCTTGATAGGAAACAGC TATGACCATCAGCTT TGTGGTCCAG-CCCAAC); tissue - $\mathrm{m} 15 \mathrm{~B}$ (5'-TGGCAGTAG CTCTC TTCCTCT) and m15R (5'-CAGCTTTGTGGTCCAGC CCAAC). PCR amplification produced a $419 \mathrm{bp}$ fragment for the blood DNA and a $200 \mathrm{bp}$ fragment for the tissue DNA. The PCR product $(15-20 \mu \mathrm{l})$ was digested for $1.5 \mathrm{~h}$ with Fnu4H1 (New England Biolabs) at $37^{\circ} \mathrm{C}$. Genotypes were visualised on $3 \%$ agarose gels stained with ethidium bromide. PCR amplification of the DNA fragments containing the Ser217Leu and Ala541Thr variants was performed in duplicate on $50 \%$ of the prostate tissue DNA samples and $20 \%$ of control samples.

\section{Statistical analysis}

Odds ratios were computed from the appropriate $2 \times 2$ contingency tables. Then Fisher's exact test was used to test if the corresponding odds ratio was equal to one. Logistic regression analyses were performed using the Stata statistical software package (Stata Corporation, Texas, USA). $P$ values greater than $5 \%$ were judged to be not significant.

\section{Results}

The average age of the control males, $61.5 \pm 11.2 \mathrm{SD}$ (range 41-92 years), was not statistically different from the average age of the cases, 60.7 years $\pm 6.3 \mathrm{SD}$ (range 43-75 years). The frequencies of the Leu217 and Thr541 alleles fit Hardy Weinberg proportions. The Thr541 allele showed linkage disequilibrium and was only 
detected in the presence of the Leu217 allele. The genotype frequencies of Leu217 and Thr541 in both case and control groups are given in Table 1.

We observed an increased frequency of Leu 217 carriers in the cases $(62.1 \%)$ versus controls $(50.3 \%)$ $(\mathrm{OR}=1.62,95 \%$ CI $1.15-2.30)$. Data were re-analysed after exclusion of Leu217/Thr541 carriers to determine if the association of disease with Leu217 was independent of the Thr541 allele (OR 1.59). The frequencies of Leu217 homozygotes in the two groups $(8.6$ versus $8.5 \%$ ) were not different. Logistic regression was performed for disease status to delineate effects of the Leu217 genotype versus age. We found no evidence of age as a confounder or modifier of disease status (Fig. 1). The frequency of Leu217 carriers was greater in cases versus controls $(P=0.0045)$.

No Thr541 homozygotes were detected in cases or controls. Out of the 20 cases that were Thr541 carriers, one was Asian and the rest were Caucasian. Preliminary analysis found that the frequency of Thr541 heterozygotes was not significantly increased in cases $(10.3 \%)$ versus controls $(7.4 \%)$ (OR 1.39, 95\% CI 0.75-2.52). A logistic regression was performed for disease status to delineate effects of genotypes versus age (Fig. 2). We observed that the relationship between the log odds of Thr541 and age depended on case-control status. Thr541 carrier frequency increased with age in the cases, but

Table 1 Summary of HPC2 genotypes for controls and incident prostate cancer cases

\begin{tabular}{lccll}
\hline Genotype & Controls & Cases & OR & $95 \%$ CI \\
\hline Ser/Ser & $261(49.7 \%)$ & $76(38.2 \%)$ & 1.00 & Ref. \\
Ser/Leu & $219(41.7 \%)$ & $106(53.3 \%)$ & 1.66 & $1.18-2.35$ \\
Leu/Leu & $45(8.6 \%)$ & $17(8.5 \%)$ & 1.30 & $0.70-2.40$ \\
Any Leu & $264(50.3 \%)$ & $123(61.8 \%)$ & 1.60 & $1.15-2.23$ \\
Ala/Ala & $486(92.6 \%)$ & $175(89.7 \%)$ & 1.00 & (Ref.) \\
Ala/Thr & $39(7.4 \%)$ & $20(10.3 \%)$ & 1.42 & $0.81-2.51$ \\
Thr/Thr & 0 & 0 & & \\
\hline
\end{tabular}

not with the male controls $(P=0.028)$. The proportion of control Thr541 carriers decreased with age but was not significant. We compared the Thr541 genotype frequencies in the male controls with those of 619 control females (Fig. 2). Both groups showed a gradual decrease in Thr541 genotype frequency with age, but this was not statistically significant.

The presence of prostate intraepithelial neoplasia (PIN) was determined from the pathology reports. The only PIN reported was high grade. PIN was more common in Leu 217 carriers $(42.3 \%)$ compared to noncarriers $(26.7 \%)$ (Table 2). The frequency of PIN appeared to be greater in the Leu/Leu homozygotes $(47.1 \%)$ than in the Ser/Leu heterozygotes $(41.5 \%)$, but the numbers are too small for this comparison. Similarly, the frequency of PIN appeared to be greater in Thr541 carriers $(50 \%)$ than non-carriers $(34.6 \%)$, but again the numbers are small.

\section{Discussion}

We compared the frequencies of two HPC2 gene missense variants in incident prostate cancer cases (radical prostatectomy tissue) and controls from the Calgary region. Using logistic regression analysis, we found evidence of an association between the Leu217 genotype and incident prostate cancer diagnosis that was independent of Thr541 carrier status. The Leu217 homozygous frequencies were similar in cases and controls, indicating that this variant does not act in a recessive manner as previously suggested (Tavtigian et al. 2000). Logistic regression analysis of Thr541 genotype showed an association with prostate cancer diagnosis. In viewing Fig. 2, this appears to be most relevant after age 65 . Accordingly, the Thr541 genotype was not associated with early age at diagnosis. The inclusion of data from families with early-onset hereditary prostate cancer in other studies may explain the lack of significance in these
Fig. 1 Probability of $\mathrm{HPC} 2$ gene Leu217 variant obtained from logistic regression

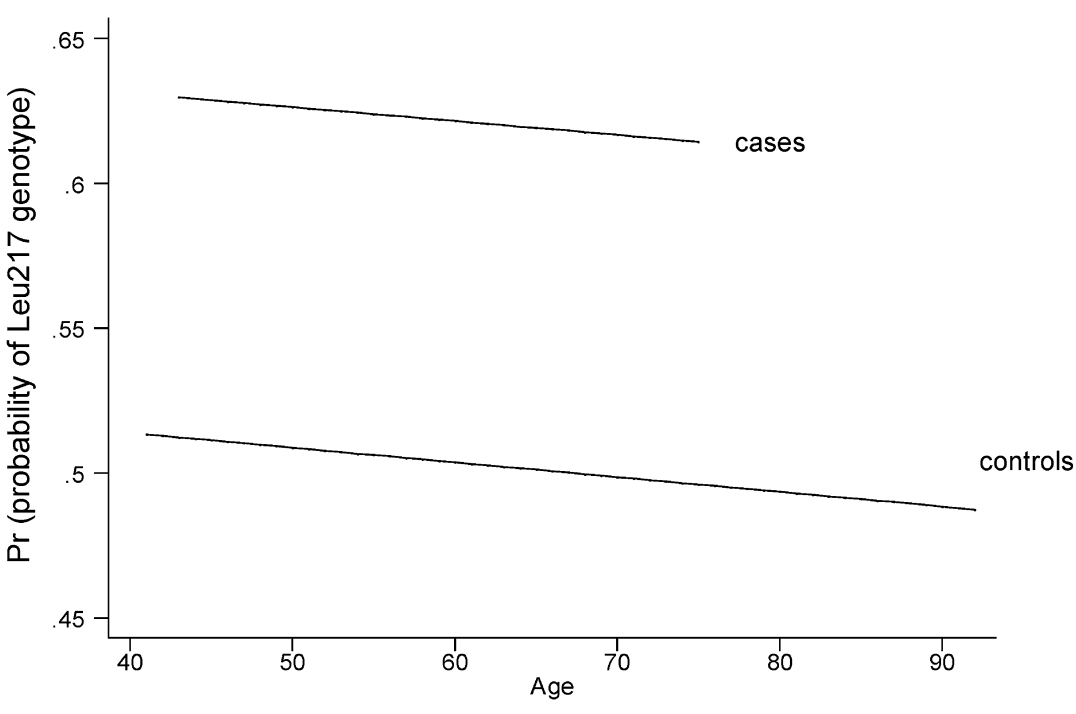


Fig. 2 Probability of $H P C 2$ gene Thr541 variant obtained from logistic regression

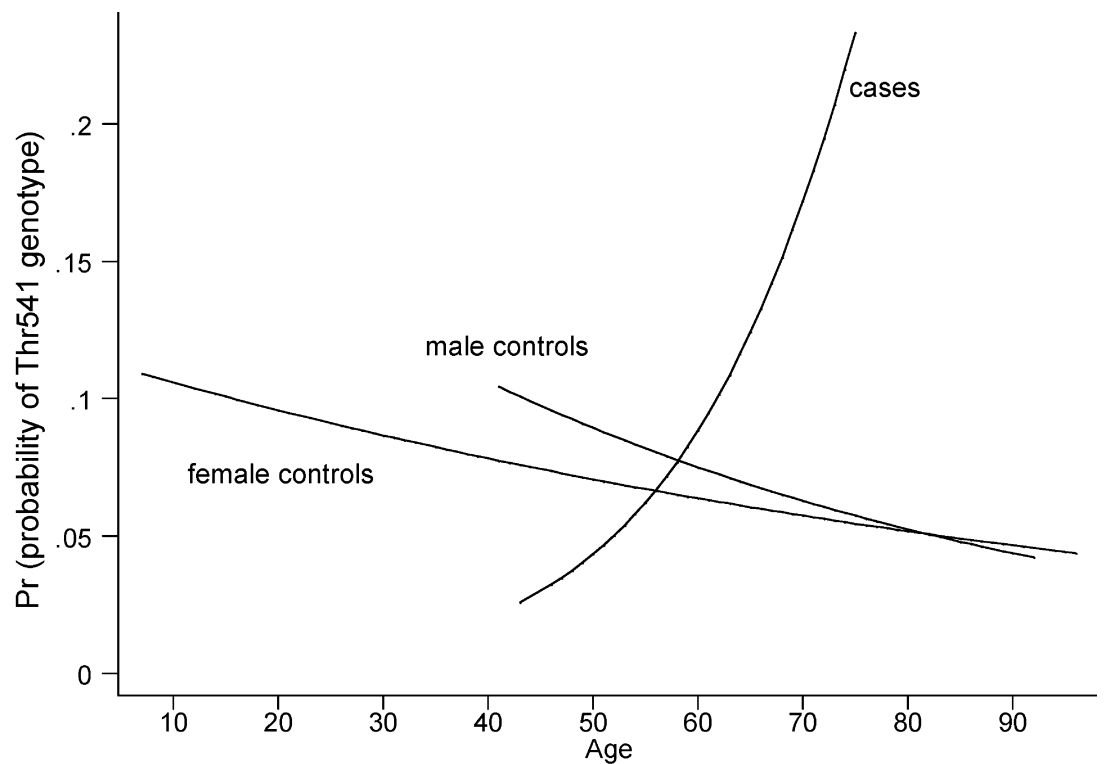

Table 2 Association of $H P C 2$ gene variants with prostate intraepithelial neoplasia (PIN)

\begin{tabular}{llll}
\hline Genotype & No. Cases with PIN $(\%)$ & OR & $(95 \%$ CI $)$ \\
\hline Ser/Ser & $20(26.7)$ & 1.0 & $($ Ref. $)$ \\
Ser/Leu & $44(41.5)$ & 1.99 & $(1.05-3.78)$ \\
Leu/Leu & $8(47.1)$ & 2.49 & $(0.84-7.33)$ \\
Any Leu & $52(42.3)$ & 2.05 & $(1.10-3.83)$ \\
Ala/Ala & $62(34.6)$ & 1.0 & $($ Ref.) \\
Any Thr & $10(50.0)$ & 1.89 & $(0.75-4.78)$ \\
\hline
\end{tabular}

works (Xu et al. 2001; Rökman et al. 2001). Our data also showed an association between the two HPC2 gene variants and PIN. PIN is predictive of an increased risk for prostate cancer, adding further support to the relationship between HPC2 gene variants and disease.

Our study identified an association between HPC2 variants and incident prostate cancer, as previously reported (Tavtigian et al. 2000; Rebbeck et al. 2000; Suarez et al. 2001; Fujiwara et al. 2002). Others studies have not found this association (Wang et al. 2001; Xu et al. 2001; Vesprini et al. 2001; Rökman et al. 2001; Shea et al. 2002; Meitz et al. 2002). Several factors may explain the differences in our results. Wang et al. (2001) genotyped hereditary prostate cancer cases with a mean age that was 11 years older than the male controls. Sixty percent of their male controls had an abnormal digital rectal exam (DRE), prostate-specific antigen (PSA) blood test, or transurethral resection of the prostate (TRUS), but were negative for prostate cancer after biopsy. In addition, some other authors appeared to use logistic regression modelling the odds of being a case rather than the odds of having the HPC2 variants. By nature of the design of such case control studies, case/ control status is a fixed variable (determined by the investigator), while HPC2 genotype is a dependent variable. Xu et al. (2001) examined hereditary prostate cancer cases, sporadic prostate cases and a smaller number of controls (normal DRE and PSA). Based on the information provided, logistic regression analysis only looked at age as a potential confounder, not as a modifier of disease status. Vesprini et al. (2001) studied sporadic prostate cancer cases, male controls with abnormal DRE, increased PSA, with or without PIN and female controls. Logistic regression analysis was not included in their results. Rökman et al. (2001) identified an association between a new HPC2 missense variant, Glu622Val, but not Leu217 or Thr541, with incident prostate cancer cases in the Finnish population. Although mentioned in the "Materials and methods" section, the authors did not present data from logistic regression modelling.

A potential limitation in the present study is that it targeted individuals treated by radical prostatectomy. The study participants represent about half of the radical prostatectomies performed each year in the Calgary region (Scott Ernst, Tom Baker Cancer Centre, personal data). The case group was younger at diagnosis (60.7 years, $\mathrm{SD} \pm 6.3)$ than men in the general Canadian population (69 years; Canadian Cancer Statistics, 2002). If the Thr541 genotype is associated with prostate cancer diagnosis after age 65 , the results of this study may underestimate of the genotype/disease relationship. The control group of males was of a similar age as the male case group. Selection was based on the absence of a cancer-related diagnosis on the haematology requisition. It is possible that some of these individuals have been diagnosed with prostate cancer or have occult disease. Using the Canadian Cancer Statistics (2002) data, we estimate that 16 out of the 525 control males $(3 \%)$ will develop prostate cancer in the next 10 years. The majority of these individuals will be age 70 or older at the time of diagnosis $(14 / 16)$. Inclusion of these 
individuals in the control group might reduce the association between Thr541 genotype and prostate cancer in the men between the ages of 60 and 75 . Thus, we would expect that our analysis of somewhat younger male cases and controls could have reduced the association between the Thr541 genotype and prostate cancer diagnosis. Larger population-based studies are needed to determine if this association is more significant than determined in this study. Larger case-control or cohort studies are needed in order to evaluate the age-related impact of the Thr541 variant on morbidity and mortality.

\section{References}

Canadian Cancer Statistics 2002, http://www.hc-sc.gc.ca

Fujiwara H, Emi M, Nagai H, Nishimura T, Konishi N, Kubota Y, Ichikawa T, Takahashi S, Shuin T, Habuchi T, Ogawa O, Inoue K, Skolnick MH, Swensen J, Camp NJ, Tavtigian SV (2002). Association of common missense changes in ELACS (HPC2) with prostate cancer in a Japanese case-control series. J Hum Genet 47:641-648

Helms C (1990) http://hdklab.wustl.edu/lab manual/dna/dna2

Meitz JC, Edwards SM, Easton DF, Murkin A, Ardern-Jones A, Jackson RA, Williams S, Dearnaley DP, Stratton MR, Houlston RS, Eeles RA; Cancer Research UK/BPG UK Familial Prostate Cancer Study Collaborators (2002) HPC2/ELAC2 polymorphisms and prostate cancer risk: analysis by age of onset of disease. Br J Cancer 87:905-908

Rebbeck TR, Walker AH, Zeigler-Jonson C, Weisburg S, Martin AM, Nathanson KL, Wein AJ, Malkowicz SB (2000) Association of $H P C 2 / E L A C 2$ genotypes and prostate cancer. Am J Hum Genet 67:1014-1019
Rökman A, Ikonen T, Mononen N, Autio V, Matikainen MP, Koivisto PA, Tammela TLJ, Kallioniemi O-P, Schleutker J (2001) ELAC2/HPC2 involvement in hereditary and sporadic prostate cancer. Cancer Res 61:6038-6041

Shea PR, Ferrell RE, Patrick AL, Kuller LH, Bunker CH (2002) ELAC2 and prostate cancer risk in Afro-Caribbeans of Tobago. Hum Genet 111:398-400

Statistics Canada, 1996 census, http://www.statcan.ca

Suarez BK, Gerhard DS, Lin J, Haberer B, Nguyen L, Kesterson NK, Catalona WJ (2001) Polymorphisms in the prostate cancer susceptibility gene HPC2/ELAC2 in multiplex families and healthy controls. Cancer Res 61:4982-4984

Tavtigian SV, Simard J, Teng DHF, Abtin V, Baumgard M, Beck A, Camp NJ, Carillo AR, Chen Y, Dayananth P, Desrochers M, Dumont M, Farnham JM, Frank D, Frye C, Ghaffari S, Gupte JS, Hu R, Iliev D, Janecki T, Kort EN, Laity KE, Leavitt A, Leblanc G, McArthur-Morrison J, Pederson A, Penn B, Peterson KT, Reid JE, Richards S, Schroeder M, Smith R, Snyder SC, Swedlund B, Swensen J, Thomas A, Tranchant M, Woodland AM, Labrie F, Skolnick MH, Neuhausen S, Rommens J, Cannon-Albright LA (2000) A candidate prostate cancer susceptibility gene at chromosome 17p. Nature Genetics 27:172-180

Vesprini D, Nam RK, Trachtenberg J, Jewett MAS, Tavtigian SV, Emami M, Ho M, Toi A, Narod SA (2001) HPC2 variants and screen-detected prostate cancer. Am J Hum Genet 68:912-917

Wang L, McDonnell SK, Elkins DA, Slager SL, Christensen E, Marks AF, Cunningham JM, Peterson BJ, Jacobsen SJ, Cerhan JR, Blute ML, Schaid DJ, Thibodeau SN (2001) Role of HPC2/ ELAC2 in hereditary prostate cancer. Cancer Res 61:6494-6499

$\mathrm{Xu}$ J, Zheng SL, Carpten JD, Nupponen NN, Robbins CM, Mestre J, Moses TY, Faith DA, Kelly BD, Isaacs SD, Wiley KE, Ewing CM, Bujnovszky P, Chang B-L, Bailey-Wilson J, Bleecker ER, Walsh PC, Trent JM, Meyers DA, Isaacs WB (2001) Evaluation of linkage and association of HPC2/ELAC2 in patients with familial or sporadic prostate cancer. Am J Hum Genet 68:901-911 